\title{
Theoretical insight to intermolecular hydrogen bond interactions between methyl N-(2-pyridyl) carbamate and acetic acid: substituent effects, cooperativity and energy decomposition analysis
}

\author{
S. M. Chalanchi, A. Ebrahimi*, A. Nowroozi \\ Department of Chemistry, Computational Quantum Chemistry Laboratory, University of Sistan and Baluchestan, \\ P.O. Box 98135-674, Zahedan, Iran
}

Received June 24, 2018; Revised July 12, 2018

\begin{abstract}
In the present work, the hydrogen bond (HB) interactions between substituted syn and anti rotamers of methyl N-(2pyridyl) carbamate and acetic acid were investigated using quantum mechanical (QM) calculations. The rotamers have two typical active sites to form hydrogen bonds with acetic acid, such that four stable complexes are found on the potential energy surface. The complexes in which the oxygen atom of carbamate acts as proton acceptor are stabilized by EWSs and are destabilized by EDSs. The trend in the effects of substituents is reversed in the other two complexes, in which the nitrogen atom of ring is involved in the interaction. According to energy data, the substituent effects on the interaction energy can be expressed by Hammett constants. The natural resonance theory (NRT) model was used to investigate the charge distribution on the carbamate group and to discuss the interaction energies. The individual HB energies were estimated to evaluate their cooperative contributions on the interaction energies of the complexes. In addition, the localized molecular orbital energy decomposition analyses (LMO-EDA) demonstrate that the electrostatic interactions are the most important stabilizing components of interactions.
\end{abstract}

Keywords: Carbamate; Hydrogen bond; Substituent effects; Localized molecular orbital energy decomposition analysis (LMO-EDA).

\section{INTRODUCTION}

The carbamate functionality is a common motif in biologically active natural products, functional materials and pharmaceuticals [1-7]. Structurally, the carbamate functionality is related to amide-ester hybrid properties, which generally represent excellent chemical and proteolytic stabilities. Carbamates are extensively used as a peptide bond successor in medicinal chemistry. This is mainly due to their chemical stability and capability to penetrate cell membranes. Another unique property of carbamates is their ability to modulate inter- and intramolecular interactions with the target enzymes or receptors. The carbamate functionality imposes a degree of conformational restriction owing to the delocalization of non-bonded electrons on nitrogen into the carboxyl group. Also, the carbamate functionality takes part in hydrogen bonding via the carboxyl group and the backbone NH. Hence, substitution on the $\mathrm{O}$ - and $\mathrm{N}$-termini of a carbamate offers opportunities for modulation of biological features and improvement in stability and pharmacokinetic features [8].

The carbamate moiety plays a significant role in medicinal chemistry, not only because it is found in drugs but also for its attendance to many prodrugs [9]. In recent years, carbamate derivatives have motivated a large number of theoretical and

* To whom all correspondence should be sent: E-mail: ebrahimi@chem.usb.ac.ir experimental studies due to their application in drug design and discovery [10-24].

In the present work, the HB interactions between the syn and anti rotamers of methyl $\mathrm{N}-(2-$ pyridyl) carbamate (CA) and acetic acid (AA), as shown in Scheme 1, were evaluated by quantum chemical calculation. The selected carbamate can act as an important starting point for drug discovery, particularly in the design of enzyme inhibitors $[8,13]$. In addition, acetic acid has been chosen as a model of carboxyalkyl side chains of proteins [25-27]. For example, it can be considered the simplest molecular model of aspartic and glutamic acid side chains involved in protein-DNA pairs [28]. These amino acids are known to play key roles in maintaining the spatial structure of various proteins [29]. The structural features of complexes and the effects of substituents on the characteristics of $\mathrm{H}$-bond interactions were also especially considered.<smiles>[R]NC(=O)O[R]</smiles>

anti

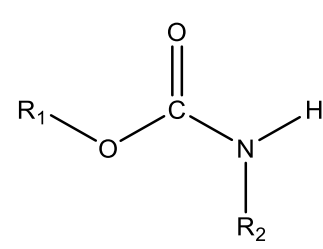

syn
Scheme 1. The syn and anti rotamers of secondary carbamates obtained by rotation about $\mathrm{C}$ (carbonyl)-N single bond. 
S. M. Chalanchi et al.: Theoretical insight to intermolecular hydrogen bond interactions between ...

The individual $\mathrm{O}-\mathrm{H} \cdots \mathrm{O}, \mathrm{O}-\mathrm{H} \cdots \mathrm{N}$ and $\mathrm{N}-\mathrm{H} \cdots \mathrm{O}$ $\mathrm{HB}$ energies were estimated to evaluate the cooperative contributions to the overall stabilization of the complexes. It is worthwhile noting that these kinds of hydrogen bonds play an important role in energetically stabilizing a ligand at the interface of an enzyme structure [30,31]. In addition, localized molecular orbital energy decomposition analyses (LMO-EDA) [32] were carried out to elucidate the strengths and properties of interactions in these hydrogen bonded systems. This information may be beneficial in further design of carbamate-based molecules as drugs or prodrugs.

\section{Computational details and methodology}

The geometry of the simulated complexes was optimized at the B3LYP/6-311++G(d,p) computational level using Gaussian 09 suite of programs [33]. The B3LYP/6-31++G(d,p) methodology was used to locate the stationary points along the potential energy surface because it is a cost-effective method and has widely been applied to H-bonded complexes as model systems [34-39]. The basis set superposition error (BSSE) was calculated by the counterpoise method of Boys and Bernardi [40]. Frequency calculations at the same level were performed to confirm that all structures are local minima on the potential energy surfaces, and to calculate the Gibbs free energies. In order to estimate the dependence of energy changes to method and basis set, the HB interaction energies were also calculated by single-point calculations using MP2 [41], M06-2X [42] and B3LYP-D3 [43] methods in conjunction with the 6$311++\mathrm{G}(\mathrm{d}, \mathrm{p})$ and aug-cc-pVTZ [44] basis sets. The solvent effects were also considered in the selfconsistent reaction-field (SCRF) calculations using the polarizable continuum model (PCM) [45]. The atoms in molecules (AIM) [46] calculations were performed by the AIM2000 program [47]. The natural resonance theory (NRT) models $[48,49]$ were used to analyze the molecular electron density in terms of resonance structures.

Two methods were considered to estimate the individual $\mathrm{HB}$ energies $\left(\Delta \mathrm{E}_{\mathrm{HB}}\right)$ in the complexes. In the first method, the individual $\mathrm{HB}$ energies $\left(\Delta \mathrm{E}_{\mathrm{HB}}^{\mathrm{a}}\right)$ were estimated using models structures that keep one $\mathrm{HB}$ at a time by rotating the acetic acid around the axis of that HB by approximately 90 degrees. The geometries of twisted structures (single $\mathrm{H}$ bonded, SHB) were optimized using two constraints indicated in Scheme $2, \phi \approx 90^{\circ}$ and $\theta$ is equal to the angle value obtained upon full optimization of the double H-bonded (DHB) complexes. The cooperative part of H-bond interactions $\left(\Delta \mathrm{E}_{\text {coop, tot }}\right)$ was obtained as the difference between the total binding energies of DHB complexes and the sum of the individual $\mathrm{H}$ bond energies of SHB structures (eq. 1) [3]:

$$
\Delta \mathrm{E}_{\text {coop, tot }}=\Delta \mathrm{E}-\left(\Delta \mathrm{E}_{\mathrm{HB} 1}^{\mathrm{a}}+\Delta \mathrm{E}_{\mathrm{HB} 2}^{\mathrm{a}}\right)
$$

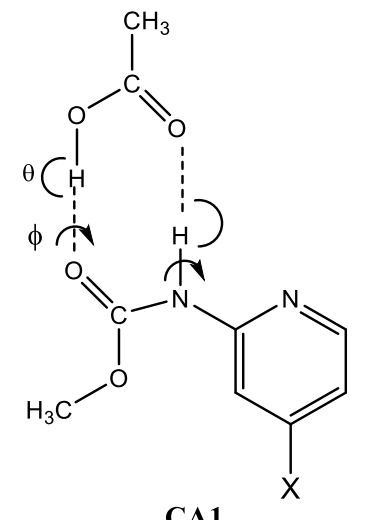<smiles></smiles>

CA2

$\mathrm{S} 1$

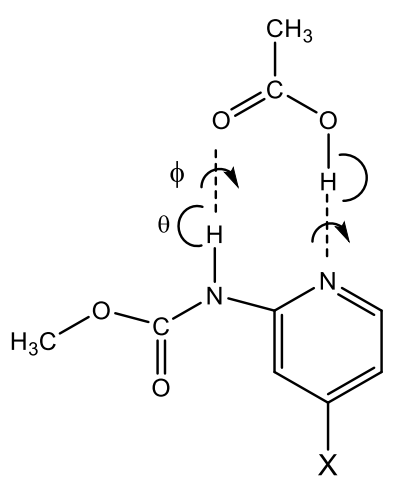

CA3

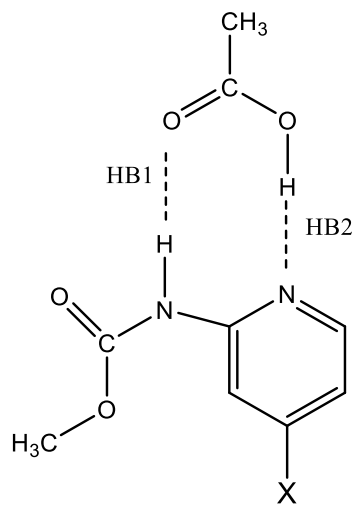

CA4
S2

$\mathrm{X}=\mathrm{F}, \mathrm{Cl}, \mathrm{COH}, \mathrm{CN}, \mathrm{NO}_{2}, \mathrm{H}, \mathrm{OH}, \mathrm{OCH}_{3}, \mathrm{NH}_{2}$, $\mathrm{NHCH}_{3}$

Scheme 2. HB interactions between the syn and anti rotamers of methyl N-(2-pyridyl) carbamate (CA) and acetic acid (AA), In the S1 series of complexes (CA1 and CA2), the oxygen atom of carbamate acts as proton acceptor in the interaction between $\mathrm{CA}$ and $\mathrm{AA}$, and in the $\mathrm{S} 2$ series of complexes (CA3 and CA4), the nitrogen atom of the ring is involved in the interaction.

In the second one, the individual $\mathrm{HB}$ energies $\left(\Delta \mathrm{E}_{\mathrm{HB}}^{b}\right)$ were estimated using the electron densities $(\rho)$ calculated using the AIM method at the H-bond critical points (HBCPs) on the basis of the following equation [51-53].

$$
\Delta \mathrm{E}_{\mathrm{HB}, \mathrm{i}}^{b}=100 \mathrm{a}_{\mathrm{i}}\left(1-\mathrm{e}^{\rho_{i}}\right)
$$

where $\rho_{i}$ is the electronic charge density calculated at the related BCP and $a_{i}$ is a fitting parameter obtained by fitting the $\Delta\left(=\Delta \mathrm{E}-\Sigma \Delta \mathrm{E}_{\mathrm{HB}, \mathrm{i}}^{b}\right)$ value to zero by the least-square method, where $\Delta \mathrm{E}$ is the total binding energy corrected with the BSSE. The cooperative part of the total HB 
S. M. Chalanchi et al.: Theoretical insight to intermolecular hydrogen bond interactions between ...

interaction $\left(\Delta \mathrm{E}_{\text {coop,tot }}\right)$ and the individual $\mathrm{HB}$ interactions $\left(\Delta \mathrm{E}_{\text {coop, }} \mathrm{HBi}\right)$ can be estimated through the following eqs.:

$$
\begin{gathered}
\Delta \mathrm{E}_{\text {coop, tot }}=\left(\Delta \mathrm{E}_{\mathrm{HB} 1}^{b}+\Delta \mathrm{E}_{\mathrm{HB} 2}^{b}\right)-\left(\Delta \mathrm{E}_{\mathrm{HB} 1}^{\mathrm{a}}+\Delta \mathrm{E}_{\mathrm{HB} 2}^{\mathrm{a}}\right) \\
=\Delta \mathrm{E}_{\text {coop, } \mathrm{HB} 1}+\Delta \mathrm{E}_{\text {coop, } \mathrm{HB} 2} \\
\Delta \mathrm{E}_{\text {coop, } \mathrm{HBi}}=\Delta \mathrm{E}_{\mathrm{HBi}}^{b}-\Delta \mathrm{E}_{\mathrm{HBi}}^{a} \mathrm{i}=1,2
\end{gathered}
$$

The localized molecular orbital energy decomposition analyses (LMO-EDA) scheme [30], as implemented in the GAMESS software [54], was applied to examine the factors contributing to binding energies. LMO-EDA scheme offers to fragment the total binding energy $(\Delta \mathrm{E})$ into electrostatic $\left(\Delta \mathrm{E}_{\text {ele }}\right)$, exchange $\left(\Delta \mathrm{E}_{\text {ex }}\right)$, repulsion $\left(\Delta \mathrm{E}_{\text {rep }}\right)$, polarization $\left(\Delta \mathrm{E}_{\mathrm{pol}}\right)$ and dispersion $\left(\Delta \mathrm{E}_{\text {disp }}\right)$ components.

$$
\Delta \mathrm{E}=\Delta \mathrm{E}^{\text {ele }}+\Delta \mathrm{E}^{\text {ex }}+\Delta \mathrm{E}^{\text {rep }}+\Delta \mathrm{E}^{\mathrm{pol}}+\Delta \mathrm{E}^{\text {disp }}
$$

Herein, the LMO-EDA scheme was also utilized for energy decomposition analysis in the SHB structures to obtain insight into the origin of the cooperative contributions. According to eqs. (1) and (5), $\Delta \mathrm{E}_{\text {coop, tot }}$ can be decomposed into the following terms:

$$
\Delta \mathrm{E}_{\text {coop, tot }}=\Delta \Delta \mathrm{E}^{\text {ele }}+\Delta \Delta \mathrm{E}^{\text {exrep }}+\Delta \Delta \mathrm{E}^{\mathrm{pol}}+\Delta \Delta \mathrm{E}^{\text {disp }}
$$

The terms on the right side of eq. (6) are the electrostatic, exchange-repulsion, polarization, and dispersion contribution, respectively, which are defined by eqs. (7) $-(10)$ :

$$
\begin{aligned}
& \Delta \Delta \mathrm{E}^{\text {ele }}=\Delta \mathrm{E}^{\text {ele }}-\left(\Delta \mathrm{E}_{\mathrm{HB} 1}^{\text {ele }}+\Delta \mathrm{E}_{\mathrm{HB} 2}^{\text {ele }}\right) \\
& \Delta \Delta \mathrm{E}^{\mathrm{pol}}=\Delta \mathrm{E}^{\mathrm{pol}}-\left(\Delta \mathrm{E}_{\mathrm{HB} 1}^{\mathrm{pol}}+\Delta \mathrm{E}_{\mathrm{HB} 2}^{\mathrm{pol}}\right) \\
& \Delta \Delta \mathrm{E}^{\text {exrep }}=\Delta \mathrm{E}^{\text {exrep }}-\left(\Delta \mathrm{E}_{\mathrm{HB} 1}^{\text {exrep }}+\Delta \mathrm{E}_{\mathrm{HB} 2}^{\text {exrep }}\right) \\
& \Delta \Delta \mathrm{E}^{\text {dis }}=\Delta \mathrm{E}^{\text {disp }}-\left(\Delta \mathrm{E}_{\mathrm{HB} 1}^{\text {disp }}+\Delta \mathrm{E}_{\mathrm{HB} 2}^{\text {disp }}\right)
\end{aligned}
$$

In eq. (9), the exchange and repulsion interactions are grouped as one exchange-repulsion term to describe the Pauli repulsion [55].

\section{RESULTS AND DISCUSSION}

\section{Geometrical parameters and interaction energies}

Quantum mechanical calculations were used to investigate the interaction between $\mathrm{CA}$ and $\mathrm{AA}$. Considering the fact that CA can simultaneously act as both proton acceptor and proton donor, four cyclic double H-bonded complexes could be obtained on the potential energy surface which were named as CA1-CA4. Scheme 2 depicts the molecular structures of the complexes CA1-CA4. In the S1 series of complexes (CA1 and CA2) the oxygen atom of carbamate acts as proton acceptor in the interaction between $\mathrm{CA}$ and $\mathrm{AA}$, whereas in the S2 series of complexes (CA3 and CA4), the nitrogen atom of the ring is involved in the interaction. Because the AIM, NRT, and LMOEDA results on both rotamers in each series are similar, the data of the complexes CA1 and CA3 were employed to show the salient features of the interactions. The results obtained for the complexes CA2 and CA4 are summarized in the Supplementary Materials. Of

The total binding energies $(\triangle \mathrm{E})$ of the complexes calculated using B3LYP, B3LYP-D3, M06-2X and MP2 methods in conjunction with the 6-311++G (d,p) and aug-cc-pVTZ basis set on the structures optimized at B3LYP/6-311++G(d,p) level and corrected for BSSE are reported in Tables 1 and S1. The BSSE correction decreases the binding energies by approximately $2 \mathrm{kcal} \mathrm{mol}^{-1}$. According to Tables 1 and $\mathrm{S} 1$, the trend in the $\Delta \mathrm{E}$ values obtained at various levels is B3LYP-D3 > MP2 > M06-2X > B3LYP. As seen, the $|\Delta E|$ values calculated using the M06-2X, MP2 and B3LYP-D3 methods with the $6-311++\mathrm{G}(\mathrm{d}, \mathrm{p})$ basis set are by 1.93-2.85, 2.11-2.98 and 3.15-3.95 larger than those calculated at the B3LYP/6-311++G(d,p) level, respectively. So the binding energies significantly depend on the method. On the other hand, changing the basis set from $6-311++\mathrm{G}(\mathrm{d}, \mathrm{p})$ to aug-cc-pVTZ increases the $|\Delta \mathrm{E}|$ values using all mentioned methods. The effect of method on the $\Delta \mathrm{E}$ values is higher than that of the basis set. Although the $\Delta \mathrm{E}$ values of complexes calculated with the B3LYPD3, MP2 and M06-2X methods are more negative than those calculated by the B3LYP method, similar trends are also observed at those levels of theory. Therefore, the results obtained at the B3LYP/6-311++G(d,p) level are used in the subsequent discussions.

As can be seen in Tables 1 and S1, interaction between CAs and AA in the S2 series is stronger than that in the S1 series, where the trend in the relative stability is CA3 (12.21) > CA4 (10.96) > CA1 $(10.61)>$ CA2 $\left(6.03 \mathrm{kcal} \mathrm{mol}^{-1}\right)$ and $\mathrm{X}=\mathrm{H} . \Delta \mathrm{E}$ of the $\mathrm{S} 1$ series of complexes becomes smaller with the electron-withdrawing substituents (EWSs) and becomes larger in the presence of the electrondonating substituents (EDSs). A reverse trend is observed for the S2 series of complexes. The highest and lowest values of $\Delta \mathrm{E}$ calculated at the B3LYP/6- 311++G (d,p) computational level in the $\mathrm{S} 1$ series of complexes correspond to the $\mathrm{NO}_{2}$ and $\mathrm{NHCH}_{3}$ substituents, respectively, and in the $\mathrm{S} 2$ series of complexes to the $\mathrm{NHCH}_{3}$ and $\mathrm{NO}_{2}$ substituents, respectively. The stabilization free energies $(\Delta \Delta G)$ of complexes calculated at the B3LYP/6-311++G(d,p) computational level are also collected in Table 1. A look at the obtained free energy values indicates that the S2 series of 
S. M. Chalanchi et al.: Theoretical insight to intermolecular hydrogen bond interactions between ...

complexes are formed more easily as compared to the $\mathrm{S} 1$ series of complexes. The large binding energies and negative Gibbs free energy changes imply that the S2 series of complexes are very stable and thermodynamically favourable (spontaneous process) to form intermolecular hydrogen bonding. Considering the $\Delta \mathrm{E}$ and $\Delta \Delta \mathrm{G}$ values, the most and the least stable complexes, i.e. CA3 and $\mathbf{C A 2}$ in the presence of $\mathrm{NHCH}_{3}$ substituent, respectively, have the most negative and the most positive value of $\Delta \Delta \mathrm{G}$ (see Table 1).

The results obtained using PCM method in the water solvent $(\varepsilon=78.39)$ at the B3LYP/6$311++\mathrm{G}(\mathrm{d}, \mathrm{p})$ computational level are gathered in Table S2. As can be seen, the binding energies of the complex CA2 suffer only a small reduction, from 0.5 to $1.5 \mathrm{kcal} / \mathrm{mol}$. It decreases by $30-35 \%$ in the complexes CA1, CA3 and CA4, which is larger than that of complex CA2. The trend in the relative stability is CA3 (10.10) > CA4 (9.86) > CA1 (8.38) $>$ CA2 $\left(5.14 \mathrm{kcal} \mathrm{mol}^{-1}\right)$ where $\mathrm{X}=\mathrm{H}$. This trend is quite similar to that predicted at the same level in the gas phase.

The substituent effects can be discussed using the resonance structures presented in Scheme 3.

The NRT model was applied within the NBO methodology [56], where four resonance structures A, B, C and D, shown in Scheme 3, were explicitly taken into account. The NRT results and the most important bond lengths of CA are gathered in Table S3. The NRT results are also graphically illustrated in Fig. 1. As can be seen, the neutral resonance weighting of CA (A) is remarkably reduced in the presence of both EWSs and EDSs. The EWSs located at the ring decrease the populations of resonance structures $\mathrm{B}$ and increase the populations of resonance structures $\mathrm{C}$ and especially $\mathrm{D}$ with higher negative charges near to the substituents. A reverse behaviour is observed in the presence of EDSs.

As shown in Fig. 1, the changes in the resonance weight of structure $\mathrm{D}$, which is in a reliable correlation with the Hammett constants $(\sigma)$, are almost twice larger than the changes in the two other ionic structures. Moreover, the changes in the resonance weight of structure D are in good correlation with the changes in the geometrical parameters of CA (see Fig. S1). Therefore, it is expected that the effects of substituents on the total interaction energy of complexes and the estimated individual $\mathrm{HB}$ energies should be in correlation with the changes in the resonance weight of structure D. In general, an increase in the resonance weight of structure D by EWSs is accompanied with an increase in the positive charge on the N3 atom (see Scheme 3) and an increase in the tendency of the $\mathrm{N}-\mathrm{H}$ group of $\mathrm{CA}$ for H-bonding with the $\mathrm{O}$ atom of $\mathrm{AA}(\mathrm{NH} . . \mathrm{O}$ bond).

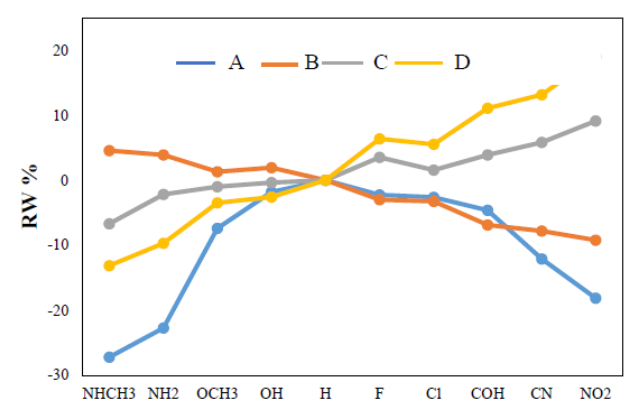

Fig. 1. Changes in the resonance weights (RW \%) calculated from natural resonance theory (NTR) for resonance structures shown in Scheme 3 in the presence of both EWSs and EDSs. [RW\% $\left.=\left(\frac{\mathrm{RW}_{\mathrm{X}}-\mathrm{RW}_{\mathrm{H}}}{\mathrm{RW}_{\mathrm{H}}}\right) \times 100\right]$

The tendency of $\mathrm{C}=\mathrm{O}$ and $-\mathrm{C}-\mathrm{O}-\mathrm{R}$ groups of $\mathrm{CA}$ for $\mathrm{H}$-bonding with the $\mathrm{O}-\mathrm{H}$ group of $\mathrm{AA}$ is reduced with increasing the resonance weight of structure $\mathrm{D}$ (O...HO bond). Also, the EWSs in CA pull the lone pair of the nitrogen atom of pyridyl inside the ring and decrease its interaction with the $\mathrm{H}$ atom of AA (N...HO bond). According to this evidence, in the $\mathrm{S} 1$ series of complexes, the EWSs have a much greater effect on the $\mathrm{NH}$... O hydrogen bond than the $\mathrm{O} \ldots \mathrm{HO}$ one (closer to $\mathrm{NH}$... O bond); thereby increasing the stability of these complexes, while in the $\mathrm{S} 2$ series the N...HO bond is more affected than the $\mathrm{NH}$... O bond and hence decreases its stability. The results are reversed for EDSs.

In addition, the relationship between the $\Delta \mathrm{E}$ values and Hammett constants $(\sigma)$ were considered to explore the generality of substitution effects on the interactions [57]. The substituent effects can be attributed to the inductive and resonance effects that exclusively correlate to the values of $\sigma_{\mathrm{m}}$ and $\sigma_{\mathrm{p}}$ constants, respectively [58]. The linear correlation coefficients ( $\mathrm{R}$ ) between the $\Delta \mathrm{E}$ values of the complexes and the $\sigma_{\mathrm{m}}$ and $\sigma_{\mathrm{p}}$ constants are equal to 0.90 and 0.98 , respectively. Herein, it would be more realistic to use $\sigma_{\mathrm{t}}\left(\sigma_{\mathrm{t}}=\left(\sigma_{\mathrm{p}}+\sigma_{\mathrm{m}}\right)\right)$ [59] as a parameter to describe the interactions. There are good linear correlations between the $\Delta \mathrm{E}$ values of complexes and $\sigma_{\mathrm{t}}$ as shown in Figs. 2 and $\mathrm{S} 2$. The higher correlation coefficients for the $\Delta \mathrm{E}-\sigma_{\mathrm{t}}$ pair $(\mathrm{R}=0.95)$ demonstrate that both inductive and resonance effects of substituents play vital roles in these intermolecular interactions. 
S. M. Chalanchi et al.: Theoretical insight to intermolecular hydrogen bond interactions between ...

Table 1. BSSE corrected binding energies $(-\Delta \mathrm{E})$ and free energy differences $(\Delta \Delta \mathrm{G})$ of complexes calculated at the B3LYP/6-311++G (d,p) ccomputational level. All energy data are given in $\mathrm{kcal} \mathrm{mol}^{-1}$.

\begin{tabular}{lllll}
\hline & CA1 & CA2 & CA3 & CA4 \\
\hline $\mathrm{NHCH}_{3}$ & $10.03(0.57)$ & $5.74(6.43)$ & $13.30(-2.84)$ & $11.92(-1.04)$ \\
$\mathrm{NH}_{2}$ & $10.16(0.50)$ & $5.79(4.77)$ & $13.13(-1.62)$ & $11.82(-0.86)$ \\
$\mathrm{OCH}_{3}$ & $10.31(0.44)$ & $5.93(4.21)$ & $12.94(-1.36)$ & $11.28(-0.54)$ \\
$\mathrm{OH}$ & $10.45(0.39)$ & $5.98(3.98)$ & $12.47(-1.23)$ & $11.19(-0.16)$ \\
$\mathrm{H}$ & $10.61(0.39)$ & $6.03(3.82)$ & $12.21(-1.21)$ & $10.96(-0.07)$ \\
$\mathrm{F}$ & $10.75(0.32)$ & $6.28(3.77)$ & $12.15(-1.13)$ & $10.90(0.08)$ \\
$\mathrm{Cl}$ & $10.86(0.25)$ & $6.30(3.79)$ & $12.03(-0.86)$ & $10.78(0.21)$ \\
$\mathrm{COH}$ & $11.03(0.13)$ & $6.34(3.70)$ & $11.57(-0.31)$ & $10.62(0.34)$ \\
$\mathrm{CN}$ & $11.13(0.04)$ & $6.40(3.69)$ & $11.48(0.08)$ & $10.43(0.42)$ \\
$\mathrm{NO}_{2}$ & $11.21(0.00)$ & $6.42(3.60)$ & $11.37(0.19)$ & $10.22(0.45)$ \\
\hline
\end{tabular}

The data in parentheses correspond to the free energy differences $(\Delta \mathrm{G})$ of the complexes.<smiles>[X]c1ccnc(N(C)C(=O)OC)c1</smiles>

A<smiles>[X]c1ccnc(N=[N+]([O-])OC)c1</smiles>

B<smiles>[X]c1ccnc(NC(=O)[O-])c1</smiles>

$\mathrm{C}$<smiles></smiles>

$\mathrm{D}$

Scheme 3. Some resonance structures of the syn rotamer of methyl N-(2-pyridyl) carbamate.

\section{AIM analysis}

The AIM analysis was carried out at the B3LYP/6-311++G (d,p) computational level to characterize the interactions.

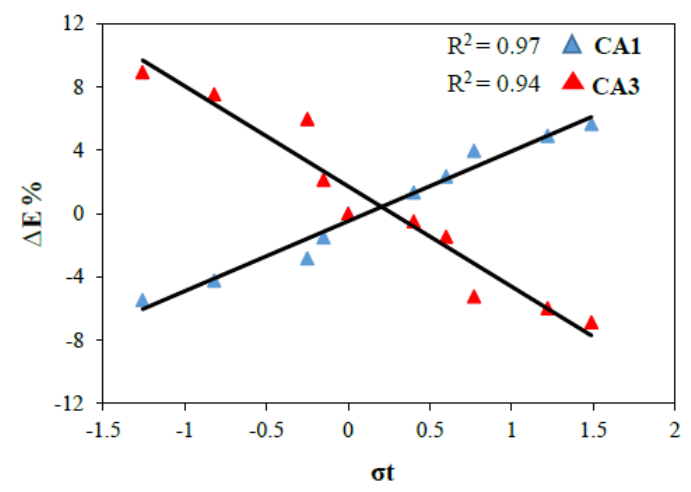

Fig. 2. Correlation between the change in the binding energies $(\Delta \mathrm{E} \%)$ and the Hammett constants $\sigma_{\text {tot }}$ of substituents for the complexes CA1 and CA3.

$$
\left[\Delta \mathrm{E} \%=\left(\frac{\Delta \mathrm{E}_{\mathrm{X}}-\Delta \mathrm{E}_{\mathrm{H}}}{\Delta \mathrm{E}_{\mathrm{H}}}\right) \times 100\right]
$$

The values of electronic charge density $(\rho)$ calculated at the bond critical points (BCPs) are listed in Table S4.

The topological properties of $\rho$ calculated at the intermolecular BCPs may be treated as the measures of $\mathrm{HB}$ strengths [60]. The $\rho$ values at the $\mathrm{NH} \cdots \mathrm{O}$ and $\mathrm{O}(\mathrm{N}) \cdots \mathrm{HO}$ hydrogen BCPs (HBCPs) 228 vary from 0.0231 to 0.0291 au and 0.0314 to $0.0560 \mathrm{au}$, respectively, which are within the ranges of hydrogen-bonded complexes values. It is well proven that the higher $\rho$ values imply the existence of stronger interactions. Hence, as presented in Table S3, the greatest $\rho_{\mathrm{BCP}}$ value of complex CA3 is observed in the presence of $\mathrm{NHCH}_{3}$ substituent, which is in agreement with its highest interaction energy. Linear correlations are observed between $\Delta \mathrm{E}$ values and the sum of $\rho$ values calculated at HBCPs $\left(\sum \rho\right)$, as is illustrated in Figs. 3 and S3.

\section{Individual hydrogen bond energies and cooperativity}

A proper evaluation of individual $\mathrm{HB}$ energies $\left(\Delta \mathrm{E}_{\mathrm{HB}}\right)$ and the cooperative contributions $\left(\Delta \mathrm{E}_{\text {coop }}\right)$ can be carried out by the characterization of mutual interplay of HBs in the CA $\cdots$ AA complexes [61]. As mentioned above, two methods were considered to estimate the $\Delta \mathrm{E}_{\mathrm{HB}}$ of complexes. The values estimated using both methods are gathered in Tables 2 and S5, and are also graphically illustrated in Figs. 4 and S4.

As can be seen in Figs. 4a and S4 (a-c), a very good correlation is observed between values estimated using the two methods. The $\Delta \mathrm{E}_{\mathrm{HB}}$ values obtained from both methods are completely in agreement with the nature of substituents and the role of atoms involved in the HBs. 
S. M. Chalanchi et al.: Theoretical insight to intermolecular hydrogen bond interactions between ...
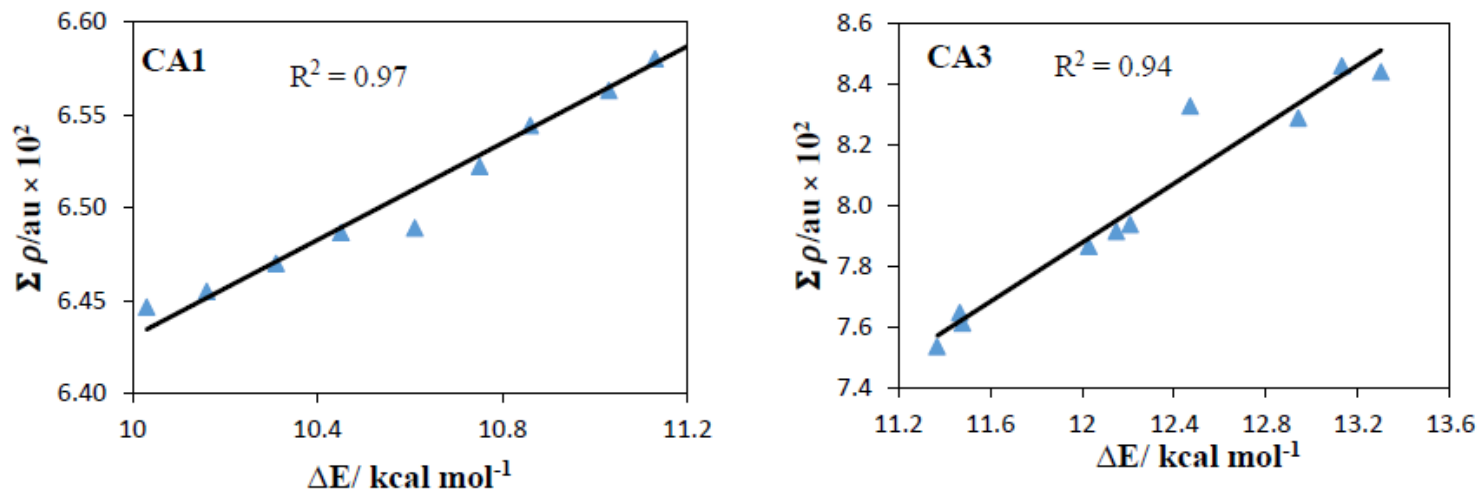

Fig. 3. Linear relationship between the sum of electron densities $\sum \rho$ calculated at HBCPs and the binding energies $\left(-\Delta \mathrm{E}\right.$ in $\left.\mathrm{kcal} \mathrm{mol}^{-1}\right)$ in the complexes CA1 and CA3.
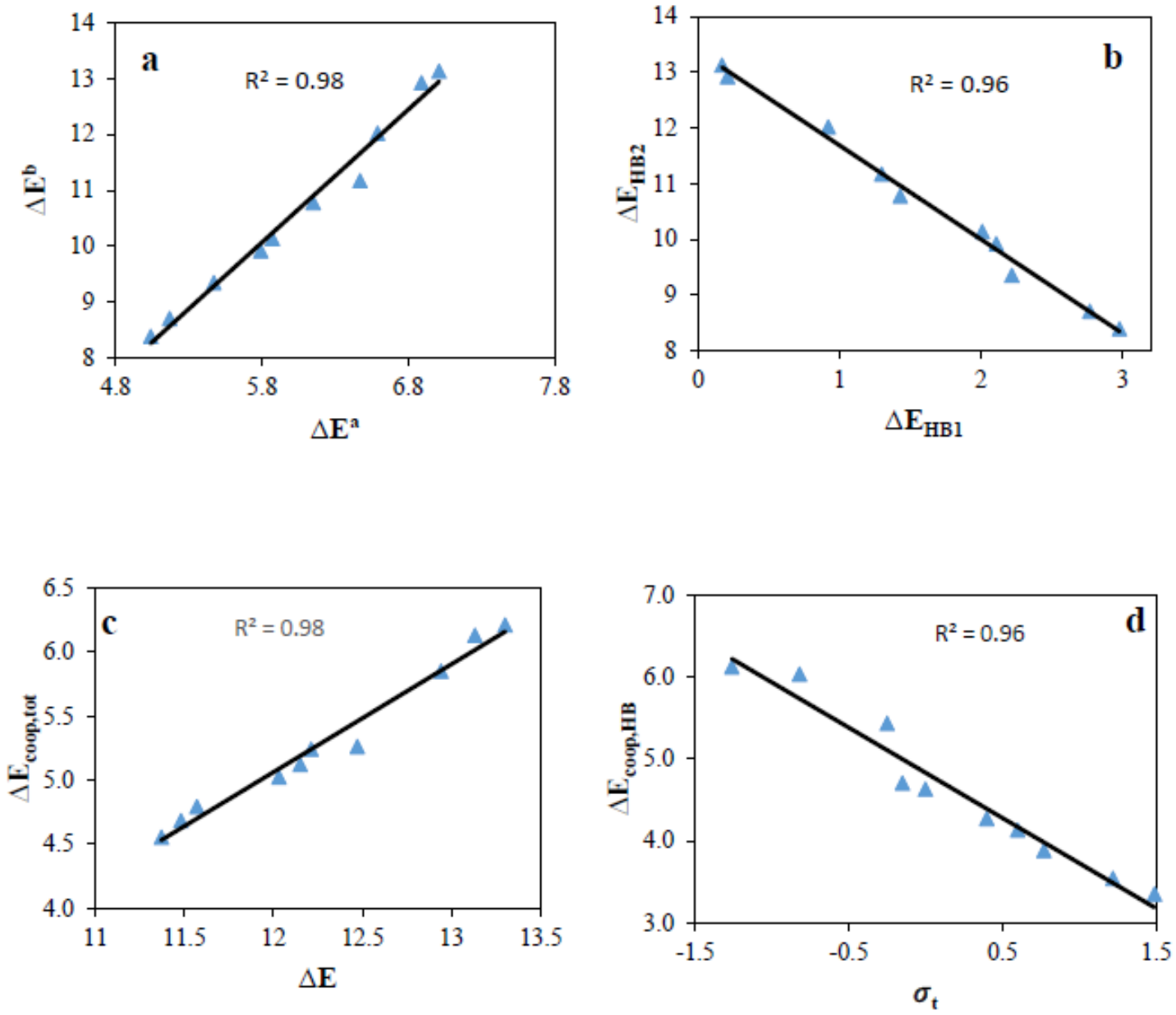

Fig. 4. (a) Correlation between the individual $\mathrm{HB}$ energies estimated using the $\mathrm{SHB}$ structures, $\Delta \mathrm{E}_{\mathrm{HB}}^{\mathrm{a}}$ and the $\rho$ values of the DHB complexes, $\Delta \mathrm{E}_{\mathrm{HB}}^{\mathrm{b}}$ for $\mathrm{HB} 2$ interaction; (b) Correlation between the $\Delta \mathrm{E}_{\mathrm{HB} 1}^{\mathrm{b}}$ and $\Delta \mathrm{E}_{\mathrm{HB} 2}^{\mathrm{b}}$; (c) Correlation between the cooperativity of total HB interaction $\left(-\Delta \mathrm{E}_{\mathrm{coop}}\right.$, tot $)$ and the binding energy $(-\Delta \mathrm{E})$; (d) Correlation between $\Delta \mathrm{E}_{\text {coop }}$ for HB2 interaction $\left(-\Delta \mathrm{E}_{\text {coop, } \mathrm{HB} 1)}\right)$ and the Hammett constants $\left(\sigma_{\text {tot }}\right)$ in the complex CA3. The HB1 and $\mathrm{HB} 2$ correspond to the $\mathrm{NH} \cdots \mathrm{O}$ and $\mathrm{N} . . . \mathrm{OH}$ interactions, respectively. All energy data are given in $\mathrm{kcal}^{\mathrm{mol}}{ }^{-1}$.

The decrease in the electron donation (or increase in the electron acceptor) power of the substituent makes $\mathrm{CA}$ a stronger $\mathrm{HB}$ donor in $\mathrm{NH} \cdots \mathrm{O}$ and rises the $\Delta \mathrm{E}_{\mathrm{HB} 1}$ value, while making $\mathrm{CA}$ a weaker $\mathrm{HB}$ acceptor in $\mathrm{O} \cdots \mathrm{HO}$ and $\mathrm{N} \cdots \mathrm{HO}$ and reducing the $\Delta \mathrm{E}_{\mathrm{HB} 2}$ value as shown in Figs. $4 \mathrm{~b}$ and S4 (d-f). In all categories, the highest and lowest values of $\Delta \mathrm{E}_{\mathrm{HB} 1}$ correspond to the strongest EWS
$\left(\mathrm{NO}_{2}\right)$ and EDS $\left(\mathrm{NHCH}_{3}\right)$, respectively; a reverse trend is observed for the $\Delta \mathrm{E}_{\mathrm{HB} 2}$ values.

The sums of the magnitudes of interactions for the individual HBs are 3.84, 1.92, 5.24 and 4.42, $\mathrm{kcal} \mathrm{mol}^{-1}$, less than the total interaction energy of the complexes CA1-CA4, respectively, where $\mathrm{X}=\mathrm{H}$ (see Tables 1 and 2). Thus, according to eq. (1), the $\Delta \mathrm{E}_{\text {coop, tot }}$ value is $36,31,42$ and $40 \%$ of the total 
S. M. Chalanchi et al.: Theoretical insight to intermolecular hydrogen bond interactions between ...

interaction energy of the complexes CA1-CA4, respectively. The $\Delta \mathrm{E}_{\text {coop, tot }}$ tends to have more negative values as the electron-withdrawing power of the substituents increases in the S1 series of the complexes. An opposite trend is observed in the S2 series of the complexes. A reliable relationship is observed between the total interaction energy of the complexes and the calculated cooperative energies as shown in Figs. 4c and S4 (g-i). As can be seen, the cooperative energies rise by the increase in the stability of complexes.

In all cases, the individual $\mathrm{HB}$ energies estimated using the $\rho$ values of the DHB complexes, $\Delta \mathrm{E}_{\mathrm{HB}}^{\mathrm{b}}$, are higher than those estimated using the SHB structures, $\Delta \mathrm{E}_{\mathrm{HB}}^{\mathrm{a}}$, in accordance with the positive cooperativity for both HBs. The trend in $\Delta \mathrm{E}_{\text {coop }}$ values estimated using eq. (4) is CA2 $(0.84)>$ CA1 $(0.74)>$ CA3 $(0.63)>$ CA4 $(0.53)$ for $\Delta \mathrm{E}_{\mathrm{HB} 1}$, where the data in parentheses are the related values in $\mathrm{kcal} \mathrm{mol}^{-1}$, which include 43, 19, 12 and $11 \%$ of the $\Delta \mathrm{E}_{\text {coop, tot }}$, respectively, where $\mathrm{X}=\mathrm{H}$ (see Table 2). The order can be discussed by comparing $\Delta \mathrm{E}_{\mathrm{HB} 1}$ and $\Delta \mathrm{E}_{\mathrm{HB} 2}$, and the related $\mathrm{HB}$ angles in each case. With respect to the weak HB2 interaction, HB1 has a better orientation and higher binding energy $\left(\Delta \mathrm{E}_{\mathrm{HB}}^{\mathrm{b}}\right)$ in the complex $\mathbf{C A 2}$ as compared with that in other complexes. Therefore, according to eq. (4), this higher binding energy makes the cooperativity more effective for HB1 in the complex CA2. In all cases, the $\Delta \mathrm{E}_{\text {coop, }} \mathrm{HB1}$ values increase as the group changes from the strongest EDS to the strongest EWS. A reverse trend is observed for the $\Delta \mathrm{E}_{\text {coop-HB2 }}$ values. These correlations are shown using $\sigma$ values in Figs. $4 d$ and S4 (j-1).

\section{Energy decomposition analysis}

To understand the nature of interactions in terms of meaningful physical components, binding energies were decomposed using the localized molecular orbital energy decomposition analyses (LMO-EDA) scheme [62]. The LMO-EDA results are summarized in Tables 3 and S6-S9, and are also graphically illustrated in Figs. 5 and S5. As can be seen, the most important stabilizing component and driving force of the interactions between CAs and $\mathrm{AA}$ is $\Delta \mathrm{E}^{\text {ele }}$, which approximately includes $41-44 \%$ of the total attraction terms; the trend in the magnitude of the terms is $\Delta \mathrm{E}^{\text {ele }}>\Delta \mathrm{E}^{\mathrm{pol}}>\Delta \mathrm{E}^{\mathrm{ex}}>$ $\Delta \mathrm{E}^{\text {disp }}$. The $\Delta \mathrm{E}^{\mathrm{pol}}, \Delta \mathrm{E}^{\mathrm{ex}}$ and $\Delta \mathrm{E}^{\text {disp }}$ values are 24,23 , and $9 \%$ of the total interaction energy in the complexes CA1, CA3 and CA4; although the $\Delta \mathrm{E}^{\mathrm{ex}}$ contribution for CA2 is not different from the rest, those of $\Delta \mathrm{E}^{\mathrm{pol}}$ and $\Delta \mathrm{E}^{\text {disp }}$ change to 19 and $14 \%$, respectively.
As can be seen in Figs. 5 and S5, the electronic effect of substituents on the $\Delta \mathrm{E}^{\mathrm{disp}}$ value is lower than other terms. Closer examination of terms reveals that the change in $\Delta \mathrm{E}^{\text {ele }}$ is larger than the values of $\Delta \mathrm{E}^{\mathrm{pol}}$ and $\Delta \mathrm{E}^{\mathrm{ex}}$. The $\Delta \mathrm{E}^{\text {ele }}$ value is mainly dependent on the charges of atoms that compose the interaction, which are directly affected by the electron donating or withdrawing nature of the substituents, whereas the covalent components $\left(\Delta \mathrm{E}^{\mathrm{pol}}\right.$ and $\Delta \mathrm{E}^{\mathrm{ex}}$ ) depend on the overlapping of orbitals that are hardly affected by the nature of the substituents. The $\Delta \mathrm{E}^{\mathrm{disp}}$ value is slightly affected by the nature of the substituent; herein, the maximum change is $0.7 \mathrm{kcal} \mathrm{mol}^{-1}$ in the complex CA3. Finally, the effect of substituent on the repulsion contribution is between those of exchange and polarization. The LMO-EDA scheme can also be used to determine the contributions of terms in the cooperativity of DHB complexes. The contributions of terms in the cooperativity estimated by eqs. (7) (10) as the difference between the LMO-EDA terms in the DHB complexes and two SHB structures, are listed in Tables 3 and S6-S9. As can be seen, the electrostatic $\left(\Delta \Delta \mathrm{E}^{\mathrm{ele}}\right)$, polarization $\left(\Delta \Delta \mathrm{E}^{\mathrm{pol}}\right)$ and repulsion interactions $\left(\Delta \Delta \mathrm{E}^{\mathrm{rep}}\right)$ make a positive contribution to the total cooperativity of the complexes, while the exchange $\left(\Delta \Delta \mathrm{E}^{\mathrm{ex}}\right)$ and dispersion $\left(\Delta \Delta \mathrm{E}^{\text {disp }}\right)$ interactions make a negative contribution to it. As mentioned above, the $\Delta \Delta \mathrm{E}^{\mathrm{ex}}$ and $\Delta \Delta \mathrm{E}^{\text {rep }}$ interactions are grouped as one exchange-repulsion $\left(\Delta \Delta \mathrm{E}^{\mathrm{exrep}}\right)$ term to describe the Pauli repulsion [Error! Bookmark not defined.]. In all cases, the $\Delta \Delta \mathrm{E}^{\text {exrep }}$ term is the largest one among all LMO-EDA terms while the $\Delta \Delta \mathrm{E}^{\text {ele }}$ term is the second-large contribution. The large negative value of $\Delta \Delta \mathrm{E}^{\text {exrep }}$ shows that the Pauli repulsion referring to the repulsive interactions between fragments is remarkably reduced when two hydrogen bond interactions operate simultaneously in DHB complexes. The negative value of the $\Delta \Delta \mathrm{E}^{\text {ele }}$ term shows that the electrostatic interaction energies between fragments are enhanced when two hydrogen bond interactions work in concert with each other in DHB complexes.

The negative value of the $\Delta \Delta \mathrm{E}^{\mathrm{pol}}$ term indicates that the orbitals in DHB complexes undergo a stronger change in their shapes in order to maximize the strength of hydrogen bonds. Finally, the positive value of the $\Delta \Delta \mathrm{E}^{\text {disp }}$ term shows that the dispersion energies are decreased in the DHB complexes. In complex CA2, the contribution of $\Delta \Delta \mathrm{E}^{\text {exrep }}$ is larger than that of $\Delta \mathrm{E}_{\text {coop, }}$ tot (see Table $3)$. It is due to the larger dispersion contribution in the formation of complex CA2. 
S. M. Chalanchi et al.: Theoretical insight to intermolecular hydrogen bond interactions between ...

Table 2. The estimated values of individual hydrogen bond energies $\left(-\Delta \mathrm{E}_{\mathrm{HB}}\right.$ in $\left.\mathrm{kcal} \mathrm{mol}^{-1}\right)$ and the cooperativity energy $\left(-\Delta \mathrm{E}_{\mathrm{COOP}}\right.$ in $\left.\mathrm{kcal} \mathrm{mol}^{-1}\right)$ in the unsubstituted complexes $(\mathrm{X}=\mathrm{H})$.

\begin{tabular}{cccccccc}
\hline & $\Delta \mathrm{E}_{\mathrm{HB} 1}^{\mathrm{a}}$ & $\Delta \mathrm{E}_{\mathrm{HB} 2}^{\mathrm{a}}$ & $\Delta \mathrm{E}_{\mathrm{HB} 1}^{\mathrm{b}}$ & $\Delta \mathrm{E}_{\mathrm{HB} 2}^{\mathrm{b}}$ & $\Delta \mathrm{E}_{\mathrm{COOP}(\mathrm{H}}$ & $\Delta \mathrm{E}_{\mathrm{COOP}(\mathrm{H}}$ & $\Delta \mathrm{E}_{\mathrm{COOP}(\mathrm{T}}$ \\
\hline $\mathrm{CA} 1$ & 1.43 & 5.39 & 2.22 & 8.39 & 0.79 & 3.00 & 3.79 \\
$\mathrm{CA} 2$ & 1.79 & 2.32 & 2.63 & 3.4 & 0.84 & 1.08 & 1.92 \\
$\mathrm{CA} 3$ & 0.82 & 6.15 & 1.43 & 10.78 & 0.62 & 4.63 & 5.24 \\
$\mathrm{CA} 4$ & 0.77 & 5.77 & 1.30 & 9.66 & 0.53 & 3.89 & 4.42 \\
\hline
\end{tabular}

$\mathrm{HB} 1$ and $\mathrm{HB} 2$ correspond to the $\mathrm{NH} \cdots \mathrm{O}$ and $\mathrm{O}(\mathrm{N}) \cdots \mathrm{H}$ hydrogen bonds, respectively; $\mathrm{a}$ and $\mathrm{b}$ correspond to the individual HB energies estimated using the SHB structures and estimated from the $\rho$ values calculated at the HBCPs of DHB complexes, respectively.

Table 3. The LMO-EDA results of unsubstituted complexes $(\mathrm{X}=\mathrm{H})$ calculated at the B3LYP/6-311++G(d,p) computational level $\left(\mathrm{kcal} \mathrm{mol}^{-1}\right)$.

\begin{tabular}{cccccccc}
\hline \multirow{2}{*}{ CA1 } & $\Delta \mathrm{E}^{\text {ele }}$ & $\Delta \mathrm{E}^{\text {ex }}$ & $\Delta \mathrm{E}^{\text {pol }}$ & $\Delta \mathrm{E}^{\text {disp }}$ & $\Delta \mathrm{E}^{\text {rep }}$ & $\Delta \mathrm{E}$ \\
& $\mathrm{DHB}$ & -24.34 & -12.66 & -12.73 & -5.78 & 42.99 & -12.52 \\
& $\mathrm{SHB} 2$ & -14.88 & -8.17 & -7.92 & -3.62 & 27.85 & -6.75 \\
& $\mathrm{SHB} 1$ & -8.01 & -4.56 & -3.77 & -2.85 & 16.55 & -2.64 \\
& $\Delta \Delta \mathrm{E}^{\mathrm{X}}$ & -1.45 & 0.07 & -1.04 & 0.69 & -1.41 & -3.13 \\
& $\mathrm{DH} 2$ & -16.6 & -8.93 & -8.23 & -5.17 & 31.56 & -7.36 \\
& $\mathrm{SHB} 2$ & -9.15 & -5.46 & -4.74 & -3.32 & 19.78 & -2.89 \\
& $\mathrm{SHB} 1$ & -7.28 & -3.79 & -3.23 & -2.61 & 14.06 & -2.86 \\
& $\Delta \Delta \mathrm{E}^{\mathrm{X}}$ & -0.17 & 0.32 & -0.26 & 0.76 & -2.28 & -1.61 \\
& $\mathrm{DHB}$ & -31.30 & -17.99 & -18.34 & -6.76 & 59.40 & -14.99 \\
& $\mathrm{SHB} 2$ & -20.47 & -12.99 & -12.63 & -4.63 & 42.76 & -7.96 \\
& $\mathrm{SHB} 1$ & -9.64 & -5.78 & -4.70 & -3.24 & 20.52 & -2.84 \\
& $\Delta \Delta \mathrm{E}^{\mathrm{X}}$ & -1.19 & 0.79 & -1.01 & 1.12 & -3.88 & -4.17 \\
& $\mathrm{DHB}$ & -29.43 & -17.27 & -17.32 & -6.63 & 57.12 & -13.52 \\
& $\mathrm{SHB} 2$ & -19.63 & -12.54 & -12.01 & -4.59 & 41.4 & -7.37 \\
& $\mathrm{SHB} 1$ & -9.09 & -5.53 & -4.50 & -3.17 & 19.67 & -2.62 \\
& $\Delta \Delta \mathrm{E}^{\mathrm{X}}$ & -0.71 & 0.80 & -0.81 & 1.13 & -3.95 & -3.53 \\
\hline
\end{tabular}

The $\Delta \Delta \mathrm{E}^{\mathrm{X}}$ values were estimated using Eqs. (7) - (10). DHB corresponds to the double H-bonded complexes and SHB1 and SHB2 correspond to the $\mathrm{NH} \cdots \mathrm{O}$ and $\mathrm{O}(\mathrm{N}){ }^{\cdots} \mathrm{H}$ hydrogen bonds, respectively.
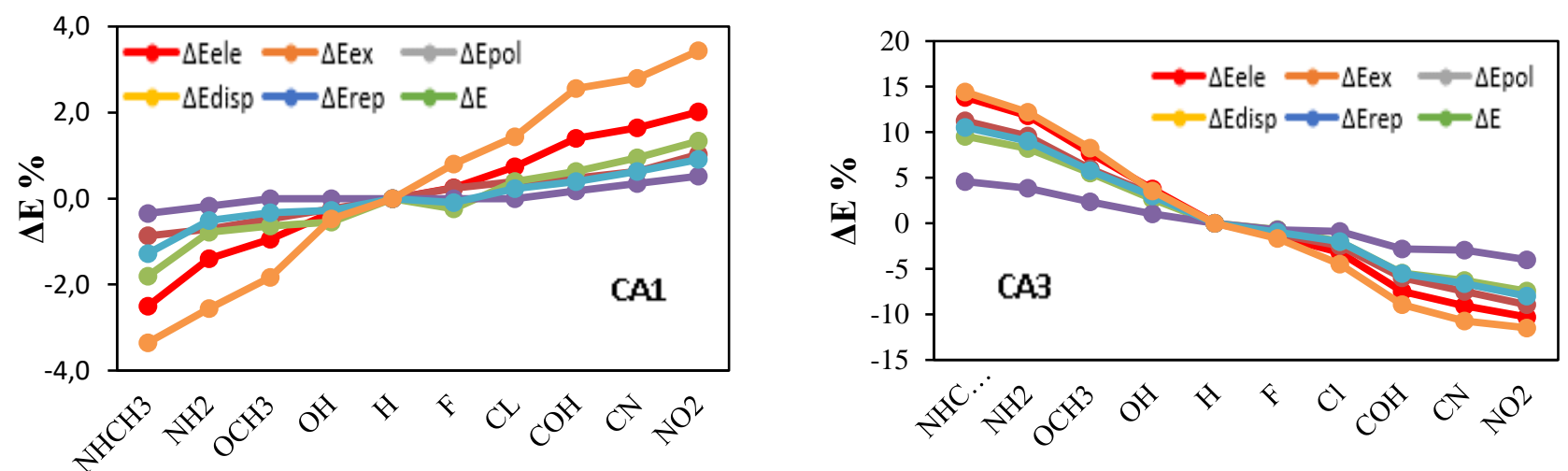

Fig. 5. The changes in energy terms $(\Delta \mathrm{E} \%)$ obtained using the LMO-EDA scheme for the complexes CA1 and CA3. $\left[\Delta \mathrm{E} \%=\left(\frac{\Delta \mathrm{E}_{\mathrm{X}}-\Delta \mathrm{E}_{\mathrm{H}}}{\Delta \mathrm{E}_{\mathrm{H}}}\right) \times 100\right]$

The negative value of $\Delta \Delta \mathrm{E}^{\text {exrep }}$ is almost cancelled out by the large positive value of the $\Delta \Delta \mathrm{E}^{\text {disp }}$, resulting in the very small $\Delta \mathrm{E}_{\text {coop, tot }}$ value for complex CA2.

\section{CONCLUSIONS}

Four cyclic double H-bonded complexes between the syn and anti rotamers of CA and AA, 
S. M. Chalanchi et al.: Theoretical insight to intermolecular hydrogen bond interactions between ...

named as CA1-CA4, were investigated on the potential energy surface. The complexes CA1 and CA2, in which the oxygen atom of CA acts as a proton acceptor, are stabilized by EWSs and are destabilized by EDSs. The behaviors of substituents are reversed in the complexes CA3 and CA4, in which the nitrogen atom of the ring is involved in the interaction. The energy data and geometrical parameters are in excellent correlations with the $\sigma$ coefficients of substituents. Very good linear correlation is observed between the individual $\mathrm{HB}$ energies estimated using (a) the SHB structures and (b) the $\rho$ values of the $\mathrm{DHB}$ complexes. The $\Delta \mathrm{E}_{\mathrm{HB}}$ values obtained from both methods are completely in agreement with the nature of substituents and the role of atoms involved in the HBs. A positive cooperativity is observed between $\mathrm{HB} 1$ and $\mathrm{HB} 2$ interactions in the DHB complexes. In addition, a linear relationship is found between the total cooperative energies and the total interaction energy of complexes. The most stable complexes are the ones showing the larger absolute values for cooperativity. The LMO-EDA scheme shows that the order of energy contribution in the stabilization of complexes is $\Delta \mathrm{E}^{\text {ele }}>\Delta \mathrm{E}^{\mathrm{pol}}>\Delta \mathrm{E}^{\mathrm{ex}}>\Delta \mathrm{E}^{\text {disp }}$, which clearly shows that the interactions are all electrostatic dominant. The LMO-EDA scheme also shows that cooperativity is mainly caused by $\Delta \Delta \mathrm{E}^{\text {exrep}}$, which indicates that the Pauli repulsion is remarkably reduced when two hydrogen bond interactions operate simultaneously.

Acknowledgement: We are grateful to the University of Sistan and Baluchestan for financial support and the Computational Quantum Chemistry Laboratory for computational facilities.

\section{REFERENCES}

1. V. J. Stella, Prodrugs: Challenges and Rewards, Springer: New York, 2007.

2. J. E. Hennessy, M. J. Latter, S. Fazelinejad, A. Philbrook, D. M. Bartkus, H. K Kim, C. J. Easton, Appl Environ Microbiol., 84, e02250-17 (2018).

3. A .K. Ghosh, B. D. Chapsal, I. T. Weber, H. Mitsuya, Acc. Chem. Res., 41, 78 (2008).

4. P. E. Chen, N.C. Anderson, Z.M. Norman, J. S. Owen, J. Am. Chem. Soc., 139, 3227 (2017).

5. I. Dierynck, H. Van Marck, M.V. Ginderen, T. H. Jonckers, M. N. Nalam, C. A. Schiffer, A. Raoof, G. Kraus, G. Picchio, Antimicrob. Agents Chemother., 55, 5723 (2011).

6. A. K. Ghosh, B. D. Chapsal, A. Baldridge, M. P. Steffey, D. E. Walters, Y. Koh, M. Amano, H. Mitsuya, J. Med. Chem., 54, 622 (2011).

7. A. K. Ghosh, C. X. Xu, K. V. Rao, A. Baldridge, J. Agniswamy, Y. F. Wang, I. T. Weber, M. Aoki, S. G. Miguel, M. Amano, H. Mitsuya, Chem. Med. Chem., 5, 1850 (2010).
8. A. K. Ghosh, M. Brindisi, J. Med. Chem., 58, 2895, (2015).

9. B. Testa, J. M. Mayer, Hydrolysis in Drug and Prodrug Metabolism-Chemistry, Biochemistry, and Enzymology; Wiley-VCH: Weinheim, Germany, 2003.

10. D. Aydin, M. Arslan, A. Sanyal, R. Sanyal, Bioconjugate Chem., 28, 1443 (2017).

11. T. K. Das, S. Mondal, R. G. Gonnade, A. T. Biju, Org. Lett., 19, 5597 (2017).

12. Y. G. Li, L. Li, M. Y. Yang, G. He, E. A. B. Kantchev, J. Org. Chem., 82, 4907 (2017).

13. H. Du, Z. Song, Y. Xu, J. Agric. Food Chem., 66, 387 (2018).

14. J. Tang, L. Hong, A. K. Ghosh, Wiley-VCH: Weinheim, Germany, 45, 413 (2010).

15. J. M. Ahn, J. C. Peters, G. C. Fu, J. Am. Chem. Soc., 139, 18101 (2017).

16. B. Z. Kurt, I. Gazioglu, A. Dag, R. E. Salmas, G. Kayı, S. Durdagi, F. Sonmez, Bioorganic Med. Chem., 25, 1352 (2017).

17. L. B. Dong, J. D. Rudolf, L. Lin, C. Ruiz, M. D. Cameron, B. Shen, Bioorganic Med. Chem., 25, 1990 (2017).

18. A. K. Ghosh, D. W. Shin, G. Koelsch, X. Lin, J. Ermolieff, J. Tang, J. Am. Chem. Soc., 122, 3522 (2000).

19. V. Gowd, H. Su, P. Karlovsky, W. Chen, Food Chem., 248, 312 (2018).

20. W. Zhou, R. Fang, Q. Chen, Food Chem., 233, 174 (2017).

21. H. Kurouchi, A. Sumita, Y. Otani, T. Ohwada, Chem. Eur. J., 20, 8682 (2014).

22. U. Das, B. Chattopadhyay, D. K. Hazra, V. V. Sureshbabu, A. K Mukherjee, J. Mol. Struct., 1122, 290 (2016).

23. C. Dugave, L. Demange, Chem. Rev., 103, 2475 (2003).

24. M. J. Deetz, M. Jonas, J. P. Malerich, B. D. Smith, Supramol. Chem., 14, 487 (2002).

25. A. C. Cheng, W. W. Chen, C. N. Fuhrmann, A. D. Frankel, J. Mol. Biol., 327, 781 (2003).

26. E. M. Basílio Janke, H. H. Limbach, K. Weisz, J. Am. Chem. Soc., 126, 2135 (2004).

27. S. Schlund, M. Mladenovic, E. M. Basílio Janke, B. Engels, K. Weisz, J. Am. Chem. Soc., 127, 16151 (2005).

28. J. Allers, Y. Shamoo, J. Mol. Biol., 311, 75 (2001).

29. O. H. O. Brovarets, Y. P. Yurenko, I. Y. Dubey, D. M. Hovorun, J Biomol Struct Dyn., 29, 1101 (2012).

30. S. Sarkhel, G. R. Desiraju, Proteins: Structure, Function, and Bioinformatics, 54, 247 (2004).

31. D. Chen, N. Oezguen, P. Urvil, C. Ferguson, S. M. Dann, T. C. Savidge, Science Advances, 2(3), e1501240 (2016).

32. P. F. Su, H. Li, J. Chem. Phys., 131, 014102 (2009).

33. M.J. Frisch, G.W. Trucks, H.B. Schlegel, G.E. Scuseria, M.A. Robb, J.R. Cheeseman, G. Scalmani, V. Barone, B. Mennucci, G.A. Petersson, H. Nakatsuji, M. Caricato, X. Li, H.P. Hratchian, A.F. Izmaylov, J. Bloino, G. Zheng, J.L. Sonnenberg, M. 
S. M. Chalanchi et al.: Theoretical insight to intermolecular hydrogen bond interactions between ...

Hada, M. Ehara, K. Toyota, R. Fukuda, J. Hasegawa, M. Ishida, T. Nakajima, Y. Honda, O. Kitao, H. Nakai, T. Vreven, J.A. Montgomery, J.E. Peralta, F. Ogliaro, M. Bearpark, J.J. Heyd, E. Brothers, K.N. Kudin, V.N. Staroverov, R. Kobayashi, J. Normand, K. Raghavachari, A. Rendell, J.C. Burant, S.S. Iyengar, J. Tomasi, M. Cossi, N. Rega, J.M. Millam, M. Klene, J.E. Knox, J.B. Cross, V. Bakken, C. Adamo, J. Jaramillo, R. Gomperts, R.E. Stratmann, O. Yazyev, A.J. Austin, R. Cammi, C. Pomelli, J.W. Ochterski, R.L. Martin, K. Morokuma, V.G. Zakrzewski, G.A. Voth, P. Salvador, J.J. Dannenberg, S. Dapprich, A.D. Daniels, O. Farkas, J.B. Foresman, J.V. Ortiz, J. Cioslowski, D.J. Fox. Gaussian09, revision A.02. Gaussian Inc., Wallingford, CT, 2009.

34. G. Subhapriya, S. Kalyanaraman, N. Surumbarkuzhali, S. Vijayalakshmi, V. Krishnakumar, S. Gandhimathi, J. Mol. Struct., 1128, 534 (2017).

35. Z. Moosavi-Tekyeh, F. Taherian, S. F. Tayyari, J. Mol. Struct., 1111, 185 (2016).

36. A. E. Shchavlev, A. N. Pankratov, A. V. Shalabay, J. Phys. Chem. A, 109, 4137 (2005).

37. I. Saada, J. K. Pearson, Comput. Theor. Chem., 969, 76 (2011).

38. R. Improta, V. Barone, J. Comput. Chem., 25, 1333 (2004).

39. A. E. Shields, T. van Mourik, J. Phys. Chem. A, 111, 13272 (2007).

40. S. F. Boys, F. Bernardi, Mol. Phys., 19, 553 (1970).

41. C. Møller, M. S. Plesset, Phys. Rev., 46, 618 (1934).

42. E. G. Hohenstein, S. T. Chill, C. D. Sherrill, J. Chem. Theory Comput., 4, 1996 (2008).

43. S. Grimme, J. Antony, S. Ehrlich, H. Krieg, J. Chem. Phys., 132, 154104 (2010).

44. J. Dunning, H. Thom, J. Chem. Phys., 901007 (1989).

45. J. Tomasi, B. Mennucci, R. Cammi, Quantum mechanical continuum solvation models, Chem. Rev., 105, 2999 (2005).
46. R. F. W. Bader, Atoms in Molecules: A Quantum Theory, Oxford University Press, Oxford, 1990.

47. K. F. Biegler, J. Schonbohm, D. Bayles, J. Comput. Chem., 22, 545 (2001).

48. E. D. Glendening, F. Weinhold, J. Comput. Chem., 19, 593 (1998).

49. E. D. Glendening, F. Weinhold, J. Comput. Chem., 19, 610 (1998)

50. A. Asensio, N. Kobko, J. J. Dannenberg, J. Phys. Chem. A, 107, 6441 (2003).

51. A. Ebrahimi, S. H. Khorassani, H. Delarami, Chemical Physics, 365, 18 (2009).

52. A. Ebrahimi, S. H. Khorassani, H. Delarami, H. Esmaeeli, J. Comput. Aided Mol., 24,409 (2010).

53. N. Hesabi, A. Ebrahimi, A. Nowroozi, J. Mol. Graph. Model., 77, 86 (2017).

54. M. W. Schmidt, K. K. Baldridge, J. A. Boatz, S. T. Elbert, M. S. Gordon, J. H. Jensen, S. Koseki, N. Matsunaga, K. A. Nguyen, S. Su, T. L. Windus, M. Dupuis, J. A. Montgomery, J. Comput. Chem., 14, 1347 (1993).

55. X. Chang, P. Su, W. Wu, Chem. Phys. Lett., 610, 246 (2014).

56. E. D. Glendening, J. K. Badenhoop, A. E. Reed, J. E. Carpenter, J. A. Bohmann, C. M. Morales, F. Weinhold, NBO 5.G, Theoretical Chemistry Institute, University of Wisconsin, Madison, WI, 2001.

57. C. Hansch, A. Leo, R.W. Taft, Chem. Rev., 97, 165 (1991).

58. F. Cozzi, F. Ponzini, R. Annunziata, M. Cinquini, J. S. Siegel, Angewandte Chemie, 34, 1019 (1995).

59. A. Ebrahimi, M. Habibi, R. S. Neyband, A. R. Gholipour, Phys. Chem. Chem. Phys., 11, 11424 (2009).

60. S. J. Grabowski, M. Małecka, J. Phys. Chem. A, 110, 11847 (2006).

61. W. Xu, X. C. Li, H. Tan, G. J. Chen, Phys. Chem. Chem. Phys., 8, 4427 (2006).

62. A. Bharti, T. Banerjee, Comput. Theor. Chem., 1067, 48 (2015). 
S. M. Chalanchi et al.: Theoretical insight to intermolecular hydrogen bond interactions between ... 